\title{
Designing a Conceptual Framework of Knowledge Management Process in Banks
}

\author{
Dr. Namrata Pancholi ${ }^{1}$, (Late) Dr. Amrata Pancholi ${ }^{2}$ \\ ${ }^{1}$ (General Managemen t,Amity International Business School, Amity University Uttar Pradesh, Noida, U.P. ) \\ ${ }^{2}$ (Department of Human Resource Managemen, Indian Institute of Management, Indore, M..P )
}

\begin{abstract}
In an era characterized by changing customer requirements, decreasing product life cycles and complex systems and processes, knowledge centric activities are becoming the primary source of sustainable competitive advantage in manufacturing and service organizations. In this regard knowledge is considered as the most important organizational resource. (Penrose 1959) ${ }^{[1]}$. It is this knowledge which has the capability to generate new knowledge, which can be disseminated to the relevant points of actions and embodied into the systems, processes, products and services.

One of the important reasons that organizations have focused on Knowledge Management is because it employs a holistic approach through the acquisition, creation, organizing, sharing and applying of knowledge. The implementation of knowledge management in an organization according to (Shankar and Gupta, 2005) ${ }^{[2]}$ involves the integration of knowledge from the domains of strategy, structure, processes, and technology, thus, making it difficult for the organizations to do so. The literature review suggests that knowledge is essential for organization's profit(Yang \&Chen,2007) ${ }^{[3]}$ as it reduces the operating cost, increases the returns to scale and adds value to the organization (Ofek and Sarvary, 2001) ${ }^{[4]}$ but Nonaka $(2007)^{[5]}$ feels that organizations of the $21^{s t}$ century are far from creating adequate knowledge-based competence necessary for gaining competitive advantage.

The difficulty for many organizations stems from the fact that there is a lack of a coherent framework to guide the implementation of Knowledge Management process in organizations' especially as we move away from simple tasks to organization-wide complex problems.

In order to understand the circulation of knowledge a simple list of elements and processes is inadequate. There is a need for a holistic framework where all are integrated into a dynamic coherent whole.

Thus this paper focuses on identifying a relevant framework for the process of capturing the knowledge flow in Banks and identifying whether different categories of banks score the same or different in terms of the process components of the knowledge management identifying the reasons and thereby suggesting the remedial measures.
\end{abstract}

Keywords: Framework, Organizational Knowledge, Tacit Knowledge and Explicit Knowledge, Knowledge Management Process.

\section{Importance of Knowledge Management for $21^{\text {st }}$ Century Organizations}

Globalization and the structural shift towards an information and knowledge society are the driving forces that have modified business structures in the 21st century. Knowledge is gaining importance and traditional production factors are being placed in the background due to the new environmental conditions affecting companies. Organizations of today deal with changing customer requirements, shorter product life cycles and complex systems and processes. All this compels the individuals and the organizations to constantly think, innovate and to perform better. Given the increasing complexity of business problem much attention has been given on understanding the factors that impact organization learning and knowledge sharing. (Zboralski, $2009)^{[6]}$

Knowledge is recognized as an important source of organizational advantage (Teece, 1998) ${ }^{[7]}$, that seeks to improve the performance of individuals and organizations through problem solving activities (Cross et al., 2001) ${ }^{[8]}$, and practice of creating leaning organization. (Senge, 1998\&200) ${ }^{[9]}$. While knowledge reduces the operating cost, increases the returns to scale and adds value to the organization (Ofek and Sarvary, 2001) ${ }^{[4]}$; Nonaka (2007) ${ }^{[5]}$ feels that organizations of the $21^{\text {st }}$ century are far from creating adequate knowledge-based competence necessary for gaining competitive advantage.

Thus, creation and sustenance of knowledge-based management competencies is a requirement for managing the knowledge systems in the modern organization. This is one of the reasons why organizations and researchers have focused on knowledge management concept.

Another important reason researchers have focused on Knowledge Management is that it employs a holistic approach through the acquisition, creation, organizing, sharing and applying of knowledge (Shankar and 
Gupta, 2005) from the domains of strategy, structure, processes and technology. The challenge is the volumes of data that organizations generate as part of their daily operations. (Chandra and Khanijo, 2011). ${ }^{[10]}$

Longitudinal field study, (Kjaergaard and Kautz 2008) ${ }^{[11]}$ suggests that rather than conducting knowledge management, organizational leaders and managers should seek to "establish" knowledge management. Establishing knowledge management means to create an environment within the organization to facilitate the creation, transfer and sharing of knowledge (Bratianu, Vasilache, 2009) ${ }^{[12]}$. In order to understand this circulation of knowledge a simple list of elements and processes is inadequate. Thus, there is a need for a holistic framework where all are integrated into a dynamic coherent whole.

Thus this paper focuses on identifying a relevant framework for the process of capturing the knowledge flow in Banks and identifying whether different categories of banks score the same or different in terms of the process components of the knowledge management, identifying the reasons and thereby suggesting the remedial measures. For this purpose at the stage one an intense study was carried out in terms of reviewing the already available models of Knowledge Management. This lead to the identification of some common elements though varying in terminology but having similar functions inside the organization. Based on the previous frameworks a new process framework encompassing the main components (access, apply, acquire, assess and assimilate) and sub components like infrastructure, layout autonomy, change and complexity, cooperation, rewards, training etc. was developed and named as 5-A Model of Knowledge Management.

\section{Knowledge Management and its relevance in Banks}

Knowledge Management is a discipline as stated by (Newman and Conrad, 2000) ${ }^{[13]}$ that seeks to improve the performance of individuals and organizations by maintaining and leveraging the present and future value of knowledge assets. It offers a framework for balancing the myriad of technologies and approaches. Newell et al (1999) ${ }^{[14]}$ suggests that there is no single definition of Knowledge Management, but in general the idea relates to "unlocking and leveraging the knowledge of individuals so that this knowledge becomes available as an organizational resource, which is not dependent on particular individuals." Enterprises are realizing how important it is to "know what they know" and be able to make maximum use of the knowledge.(Rowley, 2000) ${ }^{[15]}$. Since knowledge is information in action, this makes it difficult to know who knows what (King and Marks, $2008)^{[16]}$. On the employees' or even the management side, sharing knowledge or information may not be encouraged by both sides until and unless they recognize its benefits or effects in solving problems or its use within the decision making process. The problem may be exacerbated depending upon the organizational structure and the willingness of departments to cooperate and contribute in knowledge sharing, either individually or collectively.

Another definition of Knowledge management states that it is the planning, organizing, motivating and controlling of people, processes and systems in the organization to ensure that its knowledge-related assets are continuously improved and effectively employed (King, 2007) ${ }^{[17]}$. What is important in this definition is that $\mathrm{KM}$ involves knowledge creation, refinement, sharing, acquisition, and utilization. The most important task for the organizations' of this century will be to manage knowledge centric activities and knowledge workers (Davenport etal,1998). ${ }^{[18]}$.There is little evidence to suggest that provisions are different places such as databases, knowledge bases, filing cabinets and people's head.

As knowledge management initiatives and systems are beginning to appear in organizations, there is little research and field data to guide the development and implementation of such systems or to guide the expectations of the potential benefits of such systems.

Banks play a very important role in the economy of any nation and after the de-regulation of the market the banking sector has undergone a sea change. In order to better respond to the changes in the business environment it is essential to take advantage of its own experience and intellectual assets. Knowledge management plays an important role not only because it enables intellectual reuse but also the renewal of knowledge in banks that is possessed by employees. Therefore, it is imperative that these organizations continuously motivate their employees to share valuable information so that their intellectual capital can be leveraged. In recent years, numerous researchers and scholars had placed a great deal of emphasis on the need to create a knowledge sharing culture in organizations and to implement business strategies that are more knowledge friendly.(Gupta et al, 2009) [19].

In modern banks there is no debate about the value of Knowledge Management as a business practice. Banks, insurance companies and all other players in the competitive financial service sector have recognized that knowledge is power (Cross and Weller, 2001) ${ }^{[8]}$. The application of knowledge management in the banking industry does not really differ from other industries but the increasing complexity of banking environment makes its implementation more difficult. Banks have realized the crucial role of knowledge management in gaining an edge in this competitive field, but there have been laggards in the adoption of knowledge management usually due to wait and see attitude of what will be the true benefits and pitfalls from early adopters. Research studies conducted by(Alrawi \&Elkhati, 2009) ${ }^{[20]}$ have indicated that practices of knowledge 
management are still at the beginning stage and are not effective in their operations. A close observation in the same study also revealed the existence of barriers that a banking management has to overcome.

According to an International Data Corporation's survey conducted across more than 600 banks in Western Europe, only $20 \%$ of banks are currently applying knowledge management principles. This trend is actually more prevalent among large banks. With greater awareness of the importance of knowledge management, International Data Corporation expects this situation to change in the near future, and knowledge management will become a priority for the banking sector. Then, what is new in knowledge management in banking sector? A study has been carried out in Indian Banks and as the authors felt that to guide the implementation of Knowledge Management in Banks there is a need for a framework in banking sector, which will harness the available knowledge and structure the efforts, which these banks are already putting in though in an informal manner. Also it will provide them with a future direction.

For this purpose a number of frameworks given by different Knowledge Management scientists were studied. A preliminary study was also conducted in banks and only those elements were considered which had a relation with the creation, storage and reuse of knowledge in banks.

\section{A Review of Knowledge Management Framework}

Although there is a growing recognition of the importance of managing knowledge in organizations there is an absence of a unified framework which can guide the organizations in implementing a Knowledge Management Process in a formal way. Difficulty arises because the practices associated with managing knowledge have their roots in a variety of disciplines such as OB, Business Strategy, IT etc. Literature suggests that to understand Knowledge Management phenomena, many researchers have proposed frameworks, models and perspectives from time to time. A number of studies have addressed knowledge management process and identified some key elements of Knowledge Management phenomenon and how these elements interact with each other. They are: acquire, collaborate, integrate and experiment(Leonard-Barton, 1995); ${ }^{[21]}$ create, transfer, assemble, integrate and exploit(Teece, 1998); ${ }^{[7]}$ create, transfer and use(Skyrme \&Amidon, 1997) ${ }^{[22]}$ Some of these elements have been emphasized by each researcher in their explanation of Knowledge Management Process Framework.

Let us study these elements in each of the proposed frameworks in the table given below:

Table:1 All the frameworks mentioned below emphasizes on some of the elements of knowledge management process.

\begin{tabular}{|c|c|c|}
\hline S.No. & Frameworks & Emphasis on KM element \\
\hline 1. & Engelbart, (1992) $)^{[23]}$. & Technology \\
\hline 2. & Wiig's, $(1993)^{[24]}$. & $\begin{array}{l}\text { Creation, manifestation and use and } \\
\text { transfer of knowledge. }\end{array}$ \\
\hline 3. & Nonaka's, $(1994)^{[25]}$. & Transfer and conversion of knowledge \\
\hline 4. & Leonard \& Barton, $(1995)^{[21]}$ & Knowledge creation and diffusion. \\
\hline 6. & Choo, $(1996)^{[26]}$ & Knowledge creation and decision making. \\
\hline 7. & Szulanski's, $(1996)^{[27]}$ & Transfer \\
\hline 8. & Alavi, (1997) ${ }^{[28]}$ & Creation, leveraging and sharing. \\
\hline 9. & Sveiby,(1997) ${ }^{[29]}$ & $\begin{array}{l}\text { Creation and transfer along three } \\
\text { components; external and internal structure } \\
\text { and employee competence. }\end{array}$ \\
\hline 10. & Van der spek and Spijkervet, $(1997)^{[30]}$ & Develop, Distribute Combine, Hold \\
\hline 11. & Davenport and Prusak, $(1998)^{[3]]}$ & $\begin{array}{l}\text { Knowledge generation, codification and } \\
\text { transfer }\end{array}$ \\
\hline 12. & Bukowitz \& Williams, (1999) & $\begin{array}{l}\text { Tactical processes } \\
\text { (namely, Get, Use,Learn and Contribute). } \\
\text { Strategic processes (namely,Assess, } \\
\text { Build/Sustain and Divest). }\end{array}$ \\
\hline 13. & Holsapple \& Singh, $(2000)^{[33]}$ & $\begin{array}{lll}\text { Acquisition, } & \text { selection, } & \text { generation, } \\
\text { assimilation, } & \text { emission, } & \text { leadership, } \\
\text { coordination, control and measurement. }\end{array}$ \\
\hline 14. & $\begin{array}{l}\text { Alavi and } \\
\text { Leidner }(2001)^{[34]}\end{array}$ & Creation, storage and apply \\
\hline 15. & $\begin{array}{l}\text { Stollberg } \\
\text { et al., }(2004)^{[35]}\end{array}$ & $\begin{array}{l}\text { Identify, acquire, Preparation, allocation, } \\
\text { disseminate, usage, retention }\end{array}$ \\
\hline 16. & $\begin{array}{l}\text { Supyuenyong } \\
\text { and Islam } \\
(2006)^{[36]}\end{array}$ & $\begin{array}{l}\text { Organization, retention, } \\
\text { creation, acquisition, } \\
\text { dissemination and utilization. }\end{array}$ \\
\hline 17. & $\begin{array}{l}\text { Peachey } \\
\text { and Dianne } \\
(2005)^{[37]}\end{array}$ & $\begin{array}{l}\text { Creation, generation, } \\
\text { storage, retrieval, } \\
\text { transfer application, roles and skills . }\end{array}$ \\
\hline 18. & Lottering, F. \& Dick, A.L.,(2012) ${ }^{[38]}$ & Knowledge seeking and sharing, trust and \\
\hline
\end{tabular}




\begin{tabular}{|l|l|l|}
\hline & \multicolumn{1}{|c|}{} & loyalty \\
\hline 19. & Sensuse1,Rohajawati \&Depok(2013) & $\begin{array}{l}\text { Leadership, people, process, } \\
\text { and technology }\end{array}$ \\
\hline 20. & Yip ,Ng, Din, AbuBakar(2013) & $\begin{array}{l}\text { Knowledge identification, knowledge } \\
\text { acquisition, knowledge application, } \\
\text { knowledge sharing, knowledge creation and } \\
\text { knowledge preservation. }\end{array}$ \\
\hline
\end{tabular}

All the frameworks reviewed here do not fully cover all dimensions describing the nature of Knowledge Management. Some frameworks treat these activities at a relatively elementary level(mere use of technology, Englebart 1992) ${ }^{[21]}$ while others view them at a higher level (leadership, people,process , technology, Sensuse1,Rohajawati \&Depok(2013) ${ }^{[39]}$.

Any knowledge management framework adopted by a particular company can be successful only if it fits with the company or else it has to be further developed and modified by the users.

It may be possible, however, to develop a universal knowledge management model which will be a fit to banking organization. Based on the learning from above described literature review on knowledge management, an attempt is made to develop one guiding integrated framework for successful knowledge management implementation. The framework has all the required elements essential for knowledge transfer, sharing etc in banks. Care has been taken to consider all the basic and strategic functions of the banking industry.

This new conceptual framework named as 5-A Knowledge Management Framework will help our organizations i.e. banks to smoothly implement knowledge management initiative. The 5-A's of the framework are as follows: Access, Apply, Acquire, Assess, and Assimilate suggesting mainly the process of creation, manifestation, use, share and transfer of knowledge. This 5-A framework also takes into consideration the factors, which are the sub components of the process of knowledge management in the organization. These factors are organization structure, layout, autonomy, change and complexity, knowledge retrieval and articulation, training, rewards, systems and technology, trust and cooperation, alignment of day-to-day decisions and organizational goals.

Support for some of these selected elements can be found in the different knowledge management frameworks presented in Table 2.

Table 2: Identified influences on the knowledge management

\begin{tabular}{|c|c|c|c|c|c|c|}
\hline & Culture & Leadership & Measurement & Structure & $\begin{array}{l}\text { Reward and } \\
\text { Incentive } \\
\text { System }\end{array}$ & $\begin{array}{c}\text { Information and } \\
\text { Communication } \\
\text { technology }\end{array}$ \\
\hline $\begin{array}{l}\text { Alavi and Leidner } \\
2001^{[34]}\end{array}$ & $\sqrt{ }$ & & & $\sqrt{ }$ & & $\sqrt{ }$ \\
\hline $\begin{array}{l}\text { Booz Allen and } \\
\text { Hamilton } 2001\end{array}$ & $\sqrt{ }$ & $\sqrt{ }$ & & & $\sqrt{ }$ & $\sqrt{ }$ \\
\hline $\begin{array}{l}\text { Fouche and Botha } \\
2002^{[41]}\end{array}$ & $\sqrt{ }$ & $\sqrt{ }$ & $\sqrt{ }$ & $\sqrt{ }$ & & $\sqrt{ }$ \\
\hline Gold et al. 2001 $1^{[42]}$ & $\sqrt{ }$ & & & $\sqrt{ }$ & & $\sqrt{ }$ \\
\hline $\begin{array}{l}\text { Mertins et al. } \\
2003^{[43]}\end{array}$ & $\sqrt{ }$ & $\sqrt{ }$ & $\sqrt{ }$ & & $\sqrt{ }$ & $\sqrt{ }$ \\
\hline $\begin{array}{l}\text { Holsapple and } \\
\text { Singh } 2001[32]\end{array}$ & & $\sqrt{ }$ & $\sqrt{ }$ & & $\sqrt{ }$ & \\
\hline $\begin{array}{l}\text { Gupta and } \\
\text { Govindarajan } \\
2000^{[44]}\end{array}$ & $\sqrt{ }$ & $\sqrt{ }$ & & $\sqrt{ }$ & $\sqrt{ }$ & $\sqrt{ }$ \\
\hline
\end{tabular}

\section{Research Methodology}

4.1. In this section of the paper we first intend to discuss the Proposed 5A Knowledge Management Framework and consequently empirically test the components of knowledge management in banks. 


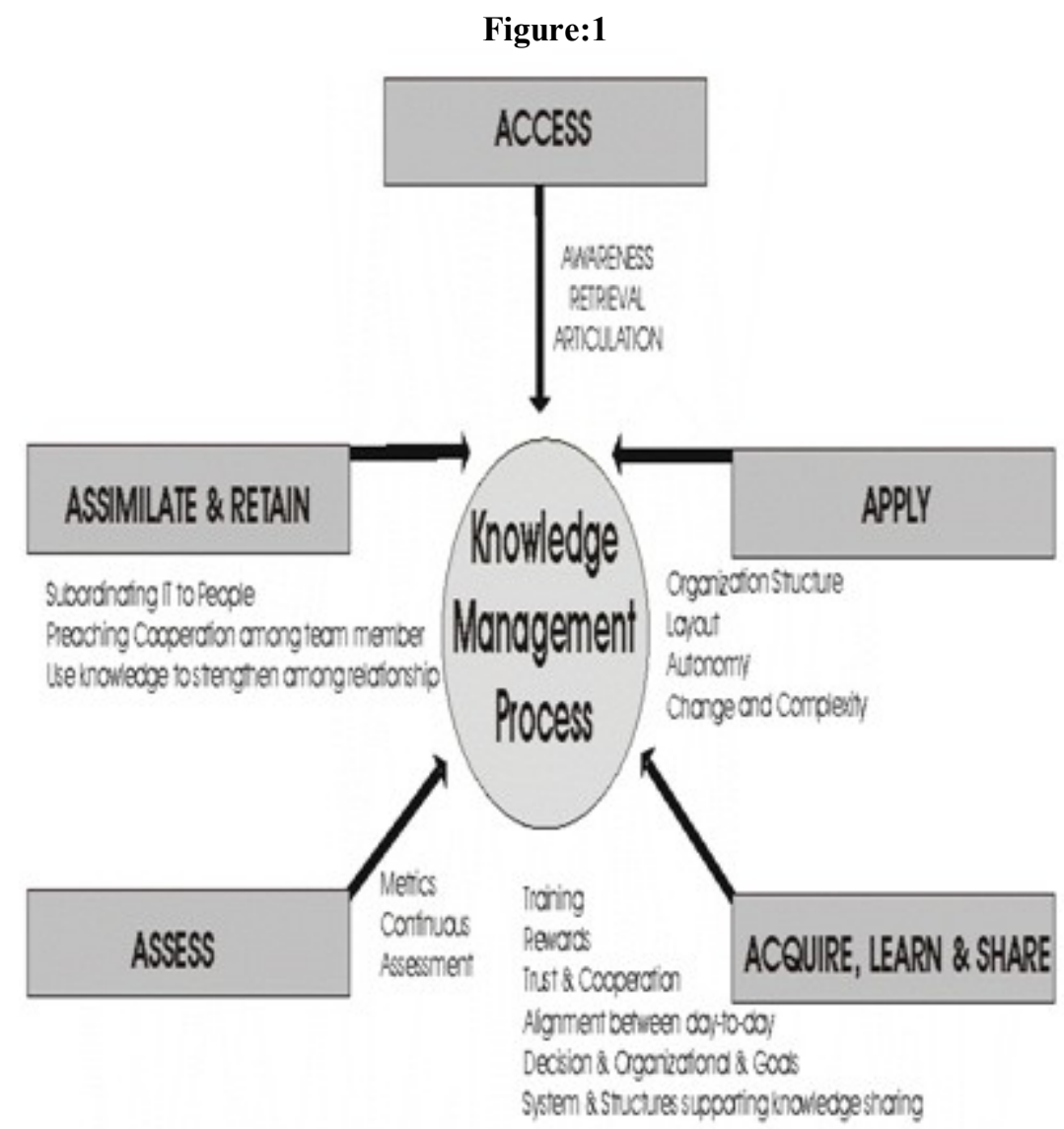

FIg 1: 5 A KNOWLEDGE MANAGEMENT PROCESS FRAMEWORK

\subsubsection{Access}

Accessing of knowledge relates to the process through which the organization can retrieve and articulate information. In order to do so the organization should provide the employees the right tools to search and capture information, i.e. the right balance of push and pull technologies and people should also be aware about as to where they can find their knowledge resources.

Therefore the various sub-elements on which the element Access will be based upon in any organization are:

- Awareness

- Retrieval

- Articulation

\subsubsection{Apply}

Once knowledge has been located and obtained, people are faced with the challenge of applying it rapidly to their specific situation. The first consideration that goes in this is that the physical environment and organization structure should be designed in a way that it encourages free flow of ideas for the easy use and application of knowledge. The organization should also pay attention to how it meets the demands of the customers according to their needs. What can help in this process is the kind of autonomy that the organization gives to its employees to use their knowledge base.

The various sub- elements on which the use or applying of knowledge is based upon are

- Organization Structure

- Layout

- Autonomy

- Change and complexity

\subsubsection{Acquire, Learn and Share}

The next step involves the process of acquiring and learning the useful knowledge which will add value for the individuals and organization. In order that the acquired knowledge is not lost it is essential to create an organizational memory. Efforts to diffuse internal knowledge and practices should also be taken into 
consideration. Establishing knowledge sharing culture and trust building in the workplace is the first step to effective Knowledge System . The movement of knowledge across individuals and organizational boundaries, into and from repositories, and into banking routines and practices is ultimately dependent on employees' knowledge sharing behaviors. "Knowledge sharing is defined as a social interaction culture, involving the exchange of employee knowledge, experiences, and skills through the whole department or organization." (Lin, Lee, \& Wang, 2009)" ${ }^{[45]}$

Organization culture plays a vital role in the success of a knowledge sharing process in banks. Knowledge Sharing process will not occur unless they are supported by the culture of the banking institution itself. (Govindrajan \& Gupta, 2000; Gummer, $1998^{[46]}$ )

The reward system is important to motivate employee performance which is consistent with the bank's strategy; that is to attract and retain the right people with the right knowledge, skills and abilities required to achieve the targeted bank's strategic goals, and create a supportive organizational culture and structure.

Last but not the least Trust plays a major role in knowledge sharing culture. Having individuals with a high propensity to trust are a possible solution to enhance the association between knowledge-centered culture and knowledge sharing in organizations. (Peralta \& Saldanha, 2014). ${ }^{[47]}$

The various sub- elements on which the learning and sharing of knowledge is based upon are

- Training

- Rewards

$\Rightarrow$ Trust and co-operation

$\Rightarrow$ Alignment between day-to-day decisions and organizational goals

$\Rightarrow \quad$ Systems and Structures supporting Knowledge Sharing.

\subsubsection{Assess}

The next step in the process should be to evaluate the existing knowledge based assets for the future needs. This requires methods for continuous assessment, a metrics or tools for assessment.

\subsubsection{Assimilate \& Retain}

Assimilation and retaining means developing knowledge assets for organization's future use. The effort of any organization at this stage should be on building systems, processes and technologies around work processes and human requirements. At this time unwanted or unnecessary information should be removed and useful information be retained.

This component of knowledge management process requires a lot of top management support for allocation of required resources. This will also include allocation of resources to the growth and maintenance of intangible assets and emphasis on collaboration with employees, suppliers, customers and even competitors as a source of competitive advantage. Assimilation of Knowledge can be done by

- Subordinating information technology to people

- Preaching cooperation among team members

- Use knowledge to strengthen the customer relationship

After developing the 5A framework of knowledge management we wanted to study the different components of the framework in banks. For this purpose the following objectives were framed.

4.2 Objectives of the study:

4.2.1. To study the components of different Knowledge Management Process frameworks.

4.2.2. To study the components of 5-A framework in Public and Private Sector banks.

4.2.3. To compare the components of 5-A framework in Public and Private Sector banks.

Since there is dearth of studies in this area and recognizing that Indian banks play a pivotal position in developing the nation's socio-economic structure, it was found necessary to empirically test the different components of Knowledge Management Process in different categories of banks.

Hence a set of null hypothesis was developed.

4.3 Hypothesis:

4.3.1. Ho: There is no significant difference in terms of Access component in private and public sector banks.

4.3.2. Ho: There is no significant difference in the Apply component of private and public sector bank.

4.3.3. Ho: There is no significant difference in the Acquire, learn and share component of private and public sector banks.

4.3.4. Ho: There is no significant difference in terms of Assess component of private and public sector banks 4.3.5. Ho: There is no significant difference in terms of Assimilate and Retain component of private and public sector banks. 
4.4 Survey Instrument

4.4.1. We planned to conduct a pilot study in cities of West India through a structured questionnaire. The sample composed of 25 managerial level employees of Public and Private sector banks and convenience sampling was done. The questionnaire provided to the participants had 60 items to be administered on a 4 point Likert scale.(1- Strongly Agree to 4-Strongly Disagree).

4.4.2.The questions were framed to suit the bank employees. It was basically aimed at an evaluation of the company's current knowledge management system - its use, different possibilities to manage knowledge, and how it fulfils the employees' needs which also helped us to understand that employees were using various knowledge resources to access, apply, acquire share, assimilate and sustain knowledge within the organization without knowing what they are actually doing is Knowledge Management.

While providing the participants with the instrument care was taken that the employees do not misunderstand that the survey instrument is only meant for knowledge management experts. Rather we were interested in understanding the Knowledge Management process practiced on a formal or informal basis in their banks and modify the final questionnaire.

4.4.3.To encourage the response each respondent was guaranteed about the confidentiality and the academic purpose of the survey. The responses were collected based on personal contact.

4.5 Measure

The 25 responses were tested for the validity and reliability of the scale. This was done by conducting a factor analysis on 25 proposed variables using the principal component method followed by varimax rotation to ensure that they are suitable for the model using SPSS16.0. On analysis 8 items were dropped due to low factor loading and the final questionnaire now consisted of 52 items with 11 questions on Access, 10 on Apply, 10 on Acquire, Learn and Share another 10 on Assess and 11 on Assimilate.

To test the internal consistency of the measure Cronbach's Alpha was used.(Nunnally, $1978^{[48]}$; Malhotra and Birks, 1999) ${ }^{[49]}$.

A generally agreed lower limit of the Cronbach's alpha coefficient is 0.7 , and Table 3 (Annexure -2 )presents the value of alpha for all dimensions is above the acceptable limit.

Table 3: Cronbach alpha test

\begin{tabular}{|l|l|}
\hline Construct & Alpha \\
\hline Access (11) & 0.89 \\
\hline Apply (10) & 0.827 \\
\hline Acquire (10) & 0.941 \\
\hline Assess (10) & 0.821 \\
\hline Assimilate (11) & 0.93 \\
\hline
\end{tabular}

4.6 Sample Description

Table 4: Sample Description

\begin{tabular}{|c|c|c|c|c|}
\hline S.No. & Demographic Variables & Classification & Samples & $\begin{array}{l}\text { Percentage } \\
\text { of Samples }\end{array}$ \\
\hline 1. & Banking Industry & $\begin{array}{l}\text { Private Sector Banks } \\
\text { Public Sector Banks }\end{array}$ & $\begin{array}{l}10 \text { Banks with } 2 \text { branches } \\
\text { of each. } \\
10 \text { Banks with } 2 \text { branches } \\
\text { of each. }\end{array}$ & $\begin{array}{l}50 \\
50\end{array}$ \\
\hline 2. & Employee Position & $\begin{array}{l}\text { Managers (=>10yrs.) } \\
\text { Officers.(>3yrs., }<10 y r s .)\end{array}$ & $\begin{array}{l}\text { Private Sector-62 } \\
\text { Public Sector-73 } \\
\text { Private Sector-138 } \\
\text { Public Sector-127 }\end{array}$ & $\begin{array}{l}31 \\
36.5 \\
69 \\
63.5 \\
\end{array}$ \\
\hline 3. & Education & $\begin{array}{l}\text { Graduation } \\
\text { Post Graduation } \\
\text { MBA and other professional } \\
\text { courses }\end{array}$ & $\begin{array}{l}\text { Private Sector-61 } \\
\text { Public Sector- } 85.40 \\
\text { Private Sector-75 } \\
\text { Public Sector-65.40 } \\
\text { Private Sector-64 } \\
\text { Public Sector-49.20 }\end{array}$ & $\begin{array}{l}30.50 \\
42.70 \\
37.50 \\
32.70 \\
\\
\\
32.00 \\
24.60\end{array}$ \\
\hline
\end{tabular}

4.6.1.The banks were chosen on the basis of already published BT KPMG survey 2012.

KPMG has also developed a view on the performance that is likely to be demonstrated by the 'Best Banks' across a few key metrics. Revenue Growth vs. Cost-to-Income ratio, Revenue Growth vs. Operating Profit Growth, Cost-to-Income ratios vs. Return on Assets, Cost/Asset vs. Revenue/Asset, Productivity and 
Efficiency, Return to Shareholders besides that the study does not consider just one performance parameter; indeed, it looks at 26 different parameters ranging from growth to quality of assets to long-term performance to rank banks.

4.6.2 Data Collection: The survey was made selecting a total of 10 public sector ( 5 top and 5 low performing banks) and 10 private sector banks(5 top and 5 low performing banks) with at least two branches of each in cities of N.W. Central India.

Therefore a total of 40 banks were surveyed. The respondents were chosen using Random Sampling Methodology whereby 400 respondents with equal number from both categories of bank were chosen. The respondents were bank managers (work experience of a minimum of 10years) and officers. The survey was carried out in the time period of January 2013- March 2014 in order to get all the respondents from sampling frame. This vigorous task was carried out through the field survey and mail questionnaire method. A great amount of help was taken from the senior managers and employees who visited the institute for participation in Management Development programs, and also from project and thesis students.

\section{Results and Discussion:}

banks.

The empirical study has pointed out some interesting findings of Knowledge Management Process in

The data collected was subjected to mean and standard deviation test.

a. For analyzing the data we compared the mean scores of the components of knowledge management process in public $\mathrm{v} / \mathrm{s}$ private sector banks.

Table: 5 Mean and Standard Deviation of Components of KMP in Public v/s Private Sector Banks

\begin{tabular}{|l|l|l|l|l|l|}
\hline S.NO.. & Components of KMP & \multicolumn{2}{|l|}{ Private Sector Banks } & \multicolumn{2}{l|}{ Public Sector Banks } \\
\hline & & Mean & SD & Mean & SD \\
\hline 1. & Access & 3.14 & .848764 & 2.735 & .99738 \\
\hline 2. & Apply & 2.885 & .960091 & 2.39 & 1.003942 \\
\hline 3. & Acquire & 1.965 & .820838 & 2.315 & .91966 \\
\hline 4. & Assess & 1.935 & .671398 & 1.88 & .64467 \\
\hline 5. & Assimilate & 2.835 & .581184 & 2.68 & .909725 \\
\hline
\end{tabular}

b. Since the components of Knowledge Management Process differ across the organizations, it is essential to test the components of Knowledge Management Process in different categories of banks using specific hypothesis.

The hypothesis specifically formulated for the study was tested using the Z-Test (Two tailed test).Table 6 .The findings of the tests are summarized below.

Table:6 The Z-Test (Two tailed test, Significance level-05)

\begin{tabular}{|l|l|l|l|l|}
\hline \multirow{2}{*}{ S.No. } & $\begin{array}{l}\text { Components of } \\
\text { KMP }\end{array}$ & $\begin{array}{l}\text { Calculated value } \\
(Z)\end{array}$ & $\begin{array}{l}\text { Critical } \\
\text { Value }\end{array}$ & S/NS \\
\hline \multirow{2}{*}{$\begin{array}{l}* .2 . \\
3 .\end{array}$} & Access & 4.332631 & 1.96 & $\mathrm{~S}$ \\
\cline { 2 - 5 } & Apply & 5.015725 & 1.96 & $\mathrm{~S}$ \\
\cline { 2 - 5 } 5. & Acquire & 4.004108 & 1.96 & $\mathrm{~S}$ \\
\cline { 2 - 5 } 5 & Assess & 0.083033 & 1.96 & $\mathrm{NS}$ \\
\cline { 2 - 5 } & Assimilate & 2.000843 & 1.96 & $\mathrm{~S}$ \\
\hline
\end{tabular}

S-Significant, NS-Not Significant

5.1 Knowledge Management Process

5.1.1 Access

a. The Private Sector banks score more on the Access component of Knowledge Management Process than the Public Sector Banks. The basic reason behind this was that retrieval and articulation of knowledge is faster in Private Sector banks as compared to the Public Sector Banks.

The Knowledge infrastructure in private sector banks is more developed and is quite comprehensive, also it was found that the employees working in the private sector banks are more techs savvy than the public sector banks, as they have joined the organization in more recent years and hence had a chance to receive a formal education in IT and computers. Further the average age of the private sector banks is lesser than the public sector banks so the employees in the public sector banks are still in the process of being trained for using the technologies.

The hypothesis was tested using

b. The hypothesis was tested using $\mathrm{Z}$ test. (two tailed test) 
1. Ho: There is no significant difference in terms of Access component in private and public sector banks.

The calculated value of $Z$-test statistics at $5 \%$ significance indicates that the difference between the Private and Public Sector banks in Access component of Knowledge Management Process is significant. Since the calculated value is more than the critical value $(4.332631>1.96)$ the null hypothesis is rejected There is a significant difference in the mean scores of Access component in Private and Public sector banks.

\subsubsection{Apply}

a.The Private Sector banks score more on the Apply component of Knowledge Management Process than the Public Sector Banks.

In spite of the availability of huge infrastructure, which lies with the public sector banks, the private sector banks make a creative use of the idle space and infrastructure. The reporting relationships do not interfere in the way the information flows and participation of employees in decision-making is more in Private Sector banks thus valuing ideas of everybody in the organization. The private sector banks in an urge to become more competitive and prove their mettle in the market they have better ability to deal with complexity and change and the new informed customer. For providing a customer friendly environment the employees are given autonomy to deal with them in their own new ways. While the public sector employees are not much bothered to apply their knowledge as they say that it nowhere connects them to any reward system and therefore are still much traditional in their approach.

b. 2.H0: There is no significant difference in the Apply component of private and public sector bank.

The calculated value of Z-test statistics at 5\% significance indicates that the difference between the Private and Public Sector banks in Apply component of Knowledge Management Process is significant. Since the calculated value is more than the critical value $(5.015725>1.96)$ the null hypothesis is rejected.

There is a significant difference in the mean scores of Apply component in Private and Public sector banks.

\subsubsection{Acquire, Learn and Share}

a. In acquiring knowledge to learn and share the Public Sector Banks have scored more than the Private Sector banks. The reason may be that the employees of Public Sector Banks are more secure in their jobs and therefore do not hesitate to share any kind of information with their colleagues, also the kind of informal meetings are more in case of Public Sector banks and hence a greater exchange of ideas takes place. Therefore one might say that the Public Sector Banks are better able to develop an environment of mutual trust and confidence among the employees to share their knowledge. Training is compulsory for both Public and Private Sector banks but the employees of Private Sector Banks are better able to take the advantage of training in IT due to their past experience and knowledge.

b. 3. Ho: There is no significant difference in the Acquire, learn and share component of private and public sector banks.

The calculated value of Z-test statistics at $5 \%$ significance indicates that the difference between the Private and Public Sector banks in Acquire component of Knowledge Management Process

is significant. Since the calculated value is more than the critical value $(4.004108>1.96)$ the null hypothesis is rejected.

There is a significant difference in the mean scores of Acquire component in Private and Public sector banks.

\subsubsection{Assess}

a.The scores of this component in general are found to be very low with no significant difference in scores in between the Public Sector Banks and Private Sector Banks. Both Public and Private Sector Banks measure their explicit knowledge through auditing. The knowledge of the individuals is assessed by conducting internal examinations from time to time, which at present is used as a performance appraisal tool and for promotions. There is no framework or metrics that can evaluate the entire organization's asset base.

b. H0: There is no significant difference in terms of Assess component of private and public sector banks The calculated value of Z-test statistics at 5\% significance indicates that the difference between the Private and Public Sector banks in Assess component of Knowledge Management Process is not significant. Since the calculated value is less than the critical value $(.083033<1.96)$ we fail to reject the null hypothesis.

There is no significant difference in the mean scores of Assess component in Private and Public sector banks.

\subsubsection{Assimilation and Retain}

a. The Private Sector Banks score more on the Assimilation and Retain component of Knowledge Management Process than the Public Sector Banks.

The private sector banks make a better use of their customer knowledge base to retain existing customers and to offer them with new services as and when required. public sector banks have taken the advantage of good HR practices to foster creativity. 
b. Ho: There is no significant difference in terms of Assimilate and Retain component of private and public sector banks.

The calculated value of Z-test statistics at 5\% significance indicates that the difference between the Private and Public Sector banks in Assimilate component of Knowledge Management Process is significant. Since the calculated value is more than the critical value $(2.000843>1.96)$ the null hypothesis is rejected. There is significant difference is the mean scores of Assimilate component in private and public sector banks.

\section{Conclusion:}

An effective Knowledge Management implementation depends upon the organizations ability to design and develop the systems and processes and to develop an environment that fosters learning, knowledge creation, knowledge sharing and the use and re-use of organizational and personal knowledge.

The difficulty for many organizations is that there is a lack of a Knowledge Management Framework that could guide the implementation of Knowledge Management effort. For the above purpose we have proposed a 5-A Framework of Knowledge Management Process for investigating knowledge management in banks. The Framework is derived by reviewing the established frameworks especially those given by (Andersens \& $\mathrm{APQC}^{[50]}, 1996$ and Bukowitz \& Williams, 1999 ${ }^{[32]}$ ). Besides this the view point of bank employees is also considered. A study and comparison the components of 5-A framework in public and private sector banks were undertaken and suggestions were made based on the above study

\subsection{Suggestions:}

Suggestions were made on the basis of the interpretation of results and interviews with bank managers and officers of public and private sector banks.

6.1.1 The Public sector banks should train their employees in the Internet usage and ways of finding information on intranet and corporate databases.

6.1.2. Both Public and Private sector banks can appoint a Knowledge Lead for responding to members queries, assisting new users with technology, maintaining timeliness, understanding anticipating the community's needs while also answering on-line questions, facilitating on-line discussions, networking within the community etc.

6.1.3. Public sector banks can make a better use of the idle space in a way that it enables a quick transfer of information thus reducing the service delivery time.

6.1.4. Both Public and Private Sector Banks should give rewards for sharing useful information.

6.1.5. Suggestions from customers should be valued by Public Sector Banks to design new products and innovate the existing ones.

6.1.6.Professional moderators and facilitators should be appointed to help people better express what they know so that others can understand it.

6.1.7.The Private Sector Banks should reduce upon the unhealthy internal competition among the employees and restrain from giving certain benefits to those who hide information.

6.1.8.Training Programs that explain the importance of co-operation among teams and sharing of knowledge among teams should be designed. (e.g. simulation exercises) by both Public and Private Sector Banks.

6.1.9.The Knowledge Sharing Behavior of both Public and Private Sector Banks should be built in the Performance Appraisal System.

6.1.10.Banks should develop a Knowledge Management Process Framework in order to assess the various jcomponents of Knowledge Management.

6.1.11 IT streamlines the processes and hence helps in effective knowledge sharing.(Shih et al,2012) ${ }^{[51]}$

For gaining maximum benefits it has to be designed around work processes and human requirements.

6.1.12. The top management should be fully involved in the designing and implementing Knowledge Management Process.

6.1.13.Inputs from the customer knowledge base can be used by the public sector banks to improve the quality and timelines of services .

6.1.14. Studies have shown that there is an interrelationship between knowledge management, organization performance and innovation.(Ciabuschi \&Martin,2012:;52] Moustaghfir \& Schiuma,2013 ${ }^{[53]}$ ). Good human resources solutions from within and outside the organization supported by IT(Massa\&Testa, 2011) ${ }^{[54]}$ can bring about creativity and innovation in banks.

6.1.15. Use of Information Technology in knowledge sharing is only a part of the total knowledge sharing in banks, face-to-face interactions are also needed .(Wang and Noe, $2010^{[55]} \&$ Shih et al. 2012)

For this purpose organizational processes and culture are as important (and this should be reflected in budgets). One has to make sure that the company is prepared for using Knowledge Management applications: it has to be clear for everybody when to share what knowledge. It is not uncommon that this raises cultural and political issues, hindering successful knowledge management, and therefore careful management is needed. 


\subsection{Limitations of the study}

Every endeavor has its own limitations, as is the case with this study. The study faced the following limitations:

- The banks covered may not truly be representative of the population since the study is focused on North West part of India.

- Although utmost care was taken to simplify the statements by revision and re-revision of the statements, Knowledge Management is comparatively a new term and therefore some of the terms may not be very clear to the respondents hence the views expressed by them might include some error.

- Studies have shown the interrelationship

The study is also extended to assess the impact of Knowledge Management Process Framework on Organization Performance in banking industry which is not integrated in this paper.

\subsection{Future Directions of Research}

- 1 .The study may be tried in different environments.

- 2.Study on individual components of Knowledge Management can be done.

Organizational knowledge is first acquired at the individual level, and effective transformation of knowledge from the individual to the organizational level is essential for knowledge to become an organizational resource.(Endres et al, 2007) ${ }^{[56]}$

"In contrast to individual knowledge, organizational knowledge is highly dynamic: it is moved by a variety of forces. If you want knowledge to move and be utilized more effectively, we need to better understand the forces that drive it" (Davenport, Prusak, 11998). All these forces came under the name integrators (Bratianu et al, 2007. ${ }^{[57]}$ An integrator is a powerful field of forces capable of combining two or more elements into a new entity, based on interdependence and synergy. The integrators proposed are management and leadership, mission and vision, technology and processes, organizational culture. In our research we have tried to study the role of some of these elements. An in-depth study can be extended to see the impact of culture, rewards and incentives, leadership and training, vision, technology on Knowledge Management.

3.An extensive study can be undertaken to find the factors influencing knowledge sharing behavior in middle management, a boundary spanning layer highly capable to influence, inform and transform information and knowledge.(Eaves, S. 2014) ${ }^{[58]}$

4.Customer satisfaction can be surveyed in order to see the impact of Knowledge Management on quality and speed of service delivery.

\section{Acknowledgement}

I express my sincere thanks to Late Prof.(Dr.)Amrata Pancholi ,HR Department, IIM Indore for conceptualizing the paper and giving the direction, suggestions and inspiration for the study. Apart of the theoretical content is written by her.

\section{References:}

[1]. E.T. Penrose, The theory of the growth of the firm,(New York, Oxford University Press, 1959).

[2]. R Shankar, A Gupta, Towards Framework for Knowledge Management, Knowledge and Process Management, 129(4), 2005, 259277.

[3]. C. Yang, L.C. Chen, Can organizational knowledge capabilities affect knowledge sharing behavior?, Journal of Information Science 33,2007, 95-109

[4]. E. Ofek, M. Sarvary, Leveraging the customer base: creating competitive advantage through knowledge management, Management Science, 47( 11), 2001,1441-1456.

[5]. I. Nonaka, The Knowledge-creating company, Harvard Business Review, 85(7-8), 2007,162-171.

[6]. K. Zboralski, Antecedents of knowledge sharing in communities of practice, Journal of Knowledge Management, 13, 2009, 90K. Z

[7]. D.J. Teece, Capturing Value from Knowledge Assets, California Management Review 40(3), 1998, 55-79.

[8]. R. Cross, S. Weller, Winning through Knowledge (Knowledge Management in Banks). Financial World, 19(2001), UK

[9]. P.M.Senge, The Practice of Innovation, Leader to Leader, 1998(9), 1998, 16-22.

[10]. A. Chandra, M.K. Khanijo, Knowledge Economy: The Indian Challenge, (New Delhi, Third Printing, Sage Publications, 2011)

[11]. A. Kjaergaard, K. Kautz, A process model of establishing knowledge management: Insights from a longitudinal field study, Omega, Oxford Press 36( 2),2008, 282.

[12]. C. Bratianu, S. Vasilache, Implementing innovation and knowledge management in the Romanian economy, Proc. $4^{\mathrm{TH}}$ International KMO Conference, Taipei, Taiwan,(UK, Academic Publishing Limited, 2009).

[13]. B.D. Newman, K.W. Conrad , A Framework for Characterizing Knowledge Management Methods, Practices, and Technologies, Proc. $3^{\text {rd }}$ International Conference on Practical Aspects of Knowledge Management ,Basel, Switzerland, 2000, 1-16.

[14]. S. Newell, J. Swan, R. Galliers, H. Scarbrough, The Intranet as a Knowledge Management Tool? Creating New Electronic Fences. In: Khosrowpour, Proc. of the IRMA International Conference on Managing Information Technology Resources in the Next Millennium, Hershey, USA, 1999, 612-619. 
[15]. J. Rowley, Is higher education ready for knowledge management?, The International Journal of Educational Management, 14(7), $2000,325-333$.

[16]. R.King, P. Marks, Motivating Knowledge Sharing Through a Knowledge Management System, OMEGA, The International Journal of Management Service, 36, 2008, 131-146.2008

[17]. R. King, Knowledge Management, A systems perspective, International Journal of Business Systems and Research, 1(1),2007, 5 28.

[18]. T.H. Davenport, D.W. De Long and M.C.Beers, Successful Knowledge Management Projects, Sloan Management Review,30, $1998,43-57$

[19]. B. Gupta, N.K. Sharma, C. Ganesh., The influence of organisational cultural values, reward, time, self-esteem and job security on knowledge sharing intentions among managers. International Journal of Indian Culture and Business Management - 2(2),2009,125 $-143$

[20]. Alrawi and S. Elkhatib , Knowledge management practices in the banking industry: Present and future state - Case study. Journal of Knowledge Management Practice,10(4), 2009

[21]. D.Leonard-Barton, Wellsprings of Knowledge: Building and Sustaining the Sources of Innovation, (Boston , Harvard Business School Press, 1995)

[22]. D.J. Skyrme, ,D.Amidon, The Knowledge agenda, Journal of Knowledge Management, 1(1), 1997, 27-37.

[23]. D. Engelbart, Toward High-Performance Organizations: A Strategic Role for Groupware, Proc. of the GroupWare Conference, San Jose, CA, 1992, Pg77-100.

[24]. K. Wiig, Knowledge Management foundations. Thinking about things. How organizations create, represent and use knowledge ,(Arlington, TX.1993 Scheme Press1993)

[25]. I.Nonaka, A dynamic theory of organizational knowledge creation". Organization Science, 5 (1), 1993, 14-37.

[26]. C.Choo, The Knowing organization: How organizations use information to construct meaning, create knowledge and make decisions . International Journal of Information Management, 16, (5),1996, 329-340.

[27]. G. Szulanski, Exploring Internal Stickiness: Impediments to the Transfer of Best Practice Within the Firm. Strategic Management Journal, 17, 1996, 27-43

[28]. M. Alavi, KPMG Peat Marwick U.S.: One Giant Brain, Harvard Business School Case,9, 1997, 397-108.

[29]. K. E .Sveiby, KE : The New Organisational Wealth - Managing and measuring Knowledge-Based Assets, (San Fransisco BerrettKoehler,1997)

[30]. R.Van der Spek, A. Spijkervet, Knowledge management: dealing intelligently with knowledge. (New York, CRC Press, ,1997)

[31]. T.H. Davenport, L. Prusak, Working knowledge: How organizations manage what they know, (Boston, Harvard Business School Press, 1998)

[32]. W.R. Bukowitz, R.L.William ,The Knowledge Management Fieldbook. Knowledge Management Process Framework, (Great Britain Pearson Education Limited, 1999).

[33]. C. Holsapple, M. Singh, The knowledge chain model: Activities for competitiveness. Expert Systems with applications, 20(1), 2001, 77-98

[34]. M. Alavi, D.E. Leidner, Knowledge management and Knowledge management systems: Conceptual foundations and Research issues, Management Information Systems Quarterly, 25 ( 1),2001, 107-136

[35]. M.Stollberg, V.Anna, D.F. Zhdanova., Hi-TechSight A Next Generation Knowledge Management Platform," Journal of information and Knowledge management 3(1),2004, 47-66

[36]. V. Supyuenyong, N. Islam, Knowledge Management Architecture: Building Blocks and Their Relationships, Technology Management for the Global Future 3, 2006, 1210 -1219.

[37]. T. Peachey, D. Hall, Knowledge Management and the Leading Information Systems Journals: An Analysis of Trends and Gaps in Published Research, International Journal of Knowledge Management, 1(3), 55-69.

[38]. F. Lottering, A.L. Dick, Integrating knowledge seeking into knowledge management models and frameworks', SA Journal of Information Management 4(1), 2012, 515 .

[39]. D.N. Sensuse, S.Rohajawati, Depok(2013), Knowledge Management: Workshop APO Framework (Case Study: Ministry of Religious Affairs of Republic Indonesia), International Journal of Computer Science Issues, 10(2), 3, 2013

[40]. M.W.Yip,H.H. Ng, S. Din, N.A. Bakar ,Knowledge Management Model for Modern Retail World Academy of Science, Engineering and Technology. International Journal of Social, Management, Economics and Business Engineering 7 (9), 2013

[41]. B. Fouché, D. F. Botha, Knowledge Management Practices in the South African Business Sector: Preliminary Findings of Longitudinal Study. South African Journal of Business Management 33 (2), 2002, 13.

[42]. A.H.Gold, A.Malhotra, A.H. Segars, Knowledge management: an organizational capabilities perspective. Journal of Management Information Systems 18(1), 2001, 185-214.

[43]. K. Mertins, Knowledge Management: Concepts and best Practices, (Berlin, Springer ,2003.)

[44]. V. Govindarajan, A.K. Gupta, (2000). Knowledge management's social dimension:Lessons from Nucor Steel, Sloan Management, $42,2000,71-80$

[45]. H. Lin, F.Lee, D.W. Wang, Evaluation of factors influencing knowledge sharing based on a fuzzy AHP approach, Journal of Information Science 36, 2009, 25-44

[46]. B. Gummer, Social relations in an organizational context: Social capital, real work, and structural holes, Journal Administration in Social Work, 22,1998, 87-105

[47]. C.F. Peralta, M.F. Saldanha, Knowledge-centered culture and knowledge sharing: the moderator role of trust propensity,Journal of Knowledge Management, 18( 3), 2014

[48]. N.K. Malhotra, D. F. Birks, Marketing research: An applied approach. (Delhi, Prentice Hall Publication,1999)

[49]. J.C. Nunnally, Psychometric theory, (New York, Mc-Graw Hill Book Company, 1978)

[50]. APQC ,Knowledge Management: Executive Summary, Consortium Benchmarking Study Best-Practice Report, American Productivity \& Quality Center, available at: www. apqc.org.(accessed 10 October 2013).]

[51]. S.C. Shih, S.H.Y. Hsu, Z. Zhu, S.K. Balasubramanian, Knowledge Sharing - A Key Role in the Downstream supply Chain, Information \& Management, 49, 2012, 70-80.

[52]. B.Ciabuschi, O.Martin, (2012), Knowledge ambiguity, innovation and subsidiary performance, Baltic Journal of Management, 7( 2), 2012, 143-166.

[53]. K. Moustaghfir, G. Schiuma, Knowledge, learning, and innovation: research and perspectives, Journal of Knowledge Management, 17( 4) 2013, 495-510

[54]. Massa , S.Testa, Knowledge domain and innovation behaviour - A framework to conceptualize KMSs in small and medium enterprises, The journal of information and knowledge management systems, 41( 4), 2011, 483-504. 
[55]. S.Wang, R.A. Noe, Knowledge Sharing: A Review and Directions for Future Research, Human Resource Management Review, 20 , 2010, 115-131

[56]. Endres, M.L., Endres, S.P., Chowdhury, S.K., Alam, I. (2007) . "Tacit knowledge sharing, self-efficacy theory, and application to the Open Source community", Journal of Knowledge Management, 11(3), pp. 92-103

[57]. Bratianu, C., Jianu, I., Vasilache, S. Integrators for organizational intellectual capital, Proceedings of the IC-Congress, INHolland University of professional education, Haarlem, The Netherlands, 2007.

[58]. S. Eaves, Middle management knowledge by possession and position: A Panoptic Examination of Individual Knowledge Sharing influences", Electronic Journal of Knowledge Management,12 (1), 2014, 63-78. 